\title{
Urban Wind Speed Analysis in Global Climate Change Perspective: Karachi as a Case Study
}

\author{
Muhammad Arif Hussain ${ }^{1}$, Muhammad Jawed Iqbal' ${ }^{2}$, Safeeullah Soomro ${ }^{3}$ \\ ${ }^{1}$ Institute of Business and Technology (BIZTEK), Karachi, Pakistan \\ ${ }^{2}$ Institute of Space \& Planetary Astrophysics, University of Karachi, Karachi, Pakistan \\ ${ }^{3}$ Sindh Madrasa Tul Islam, Karachi, Pakistan \\ Email: javiqbal@uok.edu.pk
}

Received August 20, 2012; revised September 18, 2012; accepted October 19, 2012

\begin{abstract}
It is now well known that coastal urban local climate has been showing changing pattern due to global climate change. This communication attempts to explore fluctuating pattern of urban average monthly wind speed during past 50 years (1961-2010). It shows peculiar results taking Karachi $\left(24^{\circ} 53^{\prime} \mathrm{N}, 67^{\circ} 00^{\prime} \mathrm{E}\right)$, a coastal mega-city of Pakistan, as a case study. Mann-Kendall trend test shows that March, April and October and both summer and winter seasons show positive trends for the average monthly wind speed during the whole study period (1961-2010). For the earlier 25 years data, it has been found that January, March, May, August, November and December and annual wind speed data have shown the negative trends. Only summer season has shown the positive trend for the wind speed. Similarly, for the most recent 25 years data it has been found that January, February, March, April, May, June, October, November and December and annual and both summer and winter wind speed data have shown the positive trends showing some degree of change in wind speed pattern. Probabilistic analysis reveals that average monthly wind speed data sets follow lognormal, logistic, largest extreme value, and Weibull (two- and three-parameters) probability distributions. Change point analysis has also confirmed the change in the pattern of observed average monthly wind speed data near 1992. The analysis performed reveals the effect of global warming on the local urban wind speed which appears to be temporal non-stationary.
\end{abstract}

Keywords: Urban Wind Speed Trend Analysis; Probability Distribution; Change Point Analysis

\section{Introduction}

We know that the climate system involves the interaction of the biosphere, air, sea, ice and land, with solar radiation providing the energy that drives it. On the other hand, the earth's upper atmosphere acts as a sponge, soaking up the unseen radiation. The temperature variations in the high-altitude atmosphere resulting from the switch-over of the sun from high solar activity period to diminished solar activity times and vice versa produce a cycle of decade-long changes in stratospheric winds that could produce weather changes in the lower atmosphere by some as yet-unknown mechanism [1]. The temperature of the oceans has a marked influence on the heating and moisture content of the atmosphere. Moreover, scientists have shown that global climate change has impact on local coastal and urban climate [2]. However, the link between global warming and climate change is not completely clear [3]. In addition, depletion of ozone layer has statistically significant impact on Arabian Sea [4]. Similarly, sun spots cycles and ozone layer depletion have significant correlation [5]. Furthermore, climate change might double the economic damage [6]. Analysis also shows that there exists a positive trend in the frequency of Arabian sea tropical cyclones in the past 120 years [7]. Extreme temperature in Karachi urban area also shows positive trend [8]. Arabian sea water temperature data sets near Karachi coast reveal increasing trend [9].

In general, wind regimes are dynamic in nature. So, they are sensitive to natural climate variability as well as anthropogenic-driven climate change [10], and reveal variation of wind velocity in a region [11]. Pakistan coast is about $1120 \mathrm{~km}$ long [12]. The coastal meteorology and hydrography of Karachi, the biggest city of Pakistan, is controlled by the seasonal change in the north Arabian Sea [13]. Research shows that urban wind speed decreases with the rate of urban development specially, due to construction of high rise buildings [14]. Researches have also shown that with the increase of sea surface temperature, the wind speed over sea surface is also increasing $[15,16]$. This communication attempts to investigate the changing pattern of urban monthly wind speed by analyzing past 50 years data taken at 50 meters height at the Quaid-i-Azam International Airport of Karachi. Section 2 describes data and approach of analysis. In 
Section 3, we perform trend analysis of data, while underlying distribution is tested in Section 4. To conform the findings of Sections 3 and 4, change point analysis is done in Section 5. Finally, Section 6 concludes the paper.

\section{Data and Analysis Approach}

Fifty years wind speed $(\mathrm{m} / \mathrm{s})$ data taken at 50 meters height at the Quaid-i-Azam International Airport of Karachi, have been obtained from the Pakistan Meteorological Department, Karachi. First we do trend analysis (for summer and winter seasons) by taking whole data set and then split the data set into two sets of 25 years data. To get further insights of the fluctuating behavior of wind speed, we analyze underlying probability distributions of the data. Further more, change point analysis is performed to appropriately locate the decade and the year where the wind speed pattern has changed probably as a consequence of global climate change.

Karachi has two main seasons: Summer and Winter, while spring and autumn are very short. Summer season persists for longest period during the year, from March to October, and in July and August, temperatures are modpurpose, we consider data from April to June as summer season data, and from December to February as winter season data.

\section{Trend Analysis}

This section develops trend models to serve as a guide in the assessment of impact of the global climate change on urban wind speed pattern. Linear trend model is defined as follows [18].

$$
y(t)=\alpha t+\beta
$$

where, parameters $\alpha$ and $\beta$ are estimated using least squares method, which is given as following formulae.

$$
\begin{aligned}
\alpha & =\frac{\sum y_{i} \sum t_{i}^{2}-\sum t_{i} \sum t_{i} y_{i}}{n \sum t_{i}^{2}-\left(\sum t_{i}\right)^{2}} \\
\beta & =\frac{n \sum y_{i} t_{i}-\sum t_{i} \sum y_{i}}{n \sum t_{i}^{2}-\left(\sum t_{i}\right)^{2}}
\end{aligned}
$$

Here, $t_{0}$ represents years in the wind data series with $t_{0}=1961$. Similarly, $y_{i}$ denotes average monthly wind speed. We implement the above model to wind data series and obtain the fitted models. We apply Mann-Kendall trend test [19] to test for statistically significant trends. Tables 1-3 summarize the statistically significant (at 5\% level) trend values.

It is clear from Table 1 that for the earlier 25 years (1961-1985) data January, March, May, August, November and December and annual wind speed data have shown the statistically significant negative trends. Only
Table 1. Trends of average monthly, seasonal, and annual wind speed trends for the data from 1961 to 1985. Mann Kendall trend test applied (at 5\% level).

\begin{tabular}{ll}
\hline Wind Speed & Trend Equation \\
\hline January & $y(t)=2.087-0.047 t$ \\
February & No Trend \\
March & $y(t)=2.010-0.013 t$ \\
April & No Trend \\
May & $y(t)=5.462-0.064 t$ \\
June & No Trend \\
July & No Trend \\
August & $y(t)=7.796-0.085 t$ \\
September & No Trend \\
October & No Trend \\
November & $y(t)=1.475-0.041 t$ \\
December & $y(t)=2.071-0.070 t$ \\
*Winter season & No Trend \\
${ }^{* *}$ Summer season & $y(t)=1.758+0.074 t$ \\
Annual & $y(t)=3.927-0.047 t$ \\
\hline Winter season: December to February; ${ }^{* *}$ Summer season: April to June,
\end{tabular}

Table 2. Trends of average monthly, seasonal, and annual wind speed trends for the data from 1986 to 2010. Mann Kendall trend test applied (at 5\% level).

\begin{tabular}{ll}
\hline Wind Speed & Trend Equation \\
\hline January & $y(t)=0.653+0.068 t$ \\
February & $y(t)=1.272+0.048 t$ \\
March & $y(t)=1.253+0.061 t$ \\
April & $y(t)=1.509+0.110 t$ \\
May & $y(t)=3.381+0.116 t$ \\
June & $y(t)=4.481+0.105 t$ \\
July & No Trend \\
August & No Trend \\
September & No Trend \\
October & $y(t)=0.962+0.044 t$ \\
November & $y(t)=0.356+0.047 t$ \\
December & $y(t)=1.109+0.037 t$ \\
Winter season & $y(t)=1.254+0.011 t$ \\
Summer season & $y(t)=2.132+0.064 t$ \\
Annual & $y(t)=2.595+0.062 t$ \\
\hline
\end{tabular}


Table 3. Trends of average monthly, seasonal, and annual wind speed trends for the data from 1961 to 2010. Mann Kendall trend test applied (at 5\% level).

\begin{tabular}{ll}
\hline \multicolumn{1}{c}{ Wind Speed } & Trend Equation \\
\hline January & No Trend \\
February & No Trend \\
March & $y(t)=1.640+0.012 t$ \\
April & $y(t)=1.845+0.031 t$ \\
May & No Trend \\
June & No Trend \\
July & No Trend \\
August & No Trend \\
September & No Trend \\
October & $y(t)=0.851+0.017 t$ \\
November & No Trend \\
December & No Trend \\
Winter season & $y(t)=1.223+0.004 t$ \\
Summer season & $y(t)=2.035+0.034 t$ \\
Annual & No Trend \\
\hline
\end{tabular}

summer season has shown the positive trend for the average monthly wind speed. It can be said that the earlier 25 years data reveal the impact of urban development on local coastal wind speed.

Analysis of Table 2 reveals that only for the months from July to September the wind speed data (from 1986 to 2010 , the most recent 25 years) demonstrate no trend probably due to monsoon season. It is very important to note that nine months of the year, annual and both winter and summer seasons wind speed data show positive trends. Also, the rate of increase of wind speed in the summer season is almost six times higher as compared to the rate of increase of wind speed in the winter season. The trends seem to reveal impact of global climate change on local urban monthly average wind speed observations as there are no high rise buildings near the data collection site. Increasing trend is also observed in wind speed data near Karachi coast [20]. We may say that the most recent 25 years data reveal the influence of global warming on local coastal wind speed.

Table 3 also shows trends of average monthly, annual, and seasonal wind speed data from 1961 to 2010 . Complete data set also reveal very important results regarding trends. The trends of winter and summer seasons wind speed are positive. Here, the rate of increase of wind speed in the summer season is almost nine times higher as compared to the rate of increase of wind speed in the winter season. Annual wind speed observations show no trend, but it reveals a positive trend at $\alpha=10 \%$ (not shown in the table). It is also important to note that slight negative trends are present for the months from June to September at $\alpha=10 \%$ (not shown in the table) probably due to monsoon season. Similarly, the months of January, February, November and December show slight positive trends at $\alpha=10 \%$ (not shown in the table). Statistically significant positive trends have been observed in March, April and October. In all three tables, summer season wind speed trend is positive indicating greater impact of global warming on local climatic parameters during summer.

Now, the next section gives the precise theory of probability distributions followed by the wind speed data.

\section{Probability Distributions}

The parameterization of wind speed data is based on the Log-normal and other probability distributions as described in following sub-sections, which have proven to be suitable distributions to describe the long term urban average monthly wind speed pattern $[21,22]$.

\subsection{Lognormal Distribution}

The probability distribution function, expected value and variance of lognormal distribution are defined by Equations (4) and (5).

$$
\begin{aligned}
& f_{x}(x)=\frac{1}{x \sigma \sqrt{2 \pi}} e^{-\frac{1}{2}\left(\frac{\ln x-\mu}{\sigma}\right)^{2}},(-\infty<x<+\infty), \\
& E(X)=e^{\mu+\frac{\sigma}{2}}, \operatorname{Var}(X)=e^{2 \mu+\sigma^{2}}\left(e^{\sigma^{2}}-1\right),
\end{aligned}
$$

\section{Logistics Distribution}

The logistic distribution is a continuous probability distribution. Its cumulative distribution function is the logistic function, which appears in logistic regression and feedforward neural networks. It resembles the normal distribution in shape but has heavier tails (higher kurtosis) [23]. One of the forms of the expressions of logistic distribution is given by

$$
\operatorname{Pr}[X \leq x \mathrm{I} \eta]=1-\exp \left[-\eta \beta \exp ^{\frac{-(x-\alpha)}{\beta}}\right], \quad \eta, \beta>0
$$

Next, we define Weibull distributions of two and three parameters.

\subsection{Two Parameters Weibull Distribution}

We know that Weibull probability distribution function (pdf) is the widely used model to describe wind speed fluctuations. Some times, Rayleigh distribution is also 
used to model the wind speed data [24]. The mathematical form of Weibull distribution function is given as follows:

$$
f(x)=\frac{\beta}{\eta}\left(\frac{x}{\eta}\right)^{\beta-1} e^{-\left(\frac{x}{\eta}\right)^{\beta}}, x \geq 0, \beta>1, \eta>0
$$

where parameter $\beta$ is known as the shape factor, and $\eta$ is known as the scale factor. In wind probability analysis, the variable $x$ is replaced by the wind speed, $v$.

Weibull probability distribution function parameters, estimated using the maximum likelihood (ML) method generally gives more precise results. Weibull distribution is normally used in wind energy engineering, as it conforms well to the observed long-term distribution of mean wind speeds at most sites. Next, we define three parameters Weibull probability distribution function.

\section{Three Parameters Weibull Distribution}

The three-parameter Weibull pdf is given by,

$$
f(T)=\frac{\beta}{\eta}\left(\frac{T-\gamma}{\mu}\right)^{\beta-1} e^{-\left(\frac{T-\gamma}{\eta}\right)^{\beta}}
$$

where, $T \geq 0, \beta>0, \gamma>0, \eta>0,-\infty<\gamma<\infty$ and, $\eta=$ scale parameter, $\beta=$ shape parameter, $\gamma=$ location parameter.

\subsection{Largest Extreme Value Distribution}

Largest extreme value distribution is defined by equation (9) [25].

$$
\operatorname{Pr}[X \leq x]=\exp \left[-e^{-\frac{(x-\xi)}{\theta}}\right]
$$

where $\xi>0, \theta>0$

The term "extreme value" is attached to such distributions because they can be obtained as limiting distributions of the greatest value among $n$ independent random variables.

The above distributions were fitted to the average monthly and annual wind speed data. MINITAB version 16 was used for parameters estimation and $p$-value tests. Table 4 gives the appropriate models and test results. Values of Anderson-Darling (AD) tests, used to test if a sample of data comes from a specific distribution, are also mentioned.

It is clear from Table 4 that in March, the average monthly wind speed data follows Log-normal distribution which, shows a multiplicative nature of underlying physical process, and will increase further in the long run. The wind speed in the months of November and December follow Largest Extreme Value distribution indicating a higher trend in future. These results bolster the findings of trend analysis.

As Change-point analysis provides more insights of
Table 4. Underlying probability distributions followed by average monthly and annual wind speed data. Values of Anderson-Darling (AD) tests, used to test if a sample of data comes from a specific distribution, are also mentioned.

\begin{tabular}{ll}
\hline Wind Speed & Underlying Probability Distribution \\
\hline Annual & 3-Parameter Weibull, $\mathrm{AD}=0.269, p>0.50$ \\
January & 2-Parameter Weibull, $\mathrm{AD}=0.837, p=0.028$ \\
February & 3-Parameter Weibull, $\mathrm{AD}=0.229, p>0.50$ \\
March & LogNormal, $\mathrm{AD}=0.256, p=0.712$ \\
April & 3-Parameter Weibull, $\mathrm{AD}=0.197, p>0.50$ \\
May & 2-Parameter Weibull, $\mathrm{AD}=0.355, p>0.25$ \\
June & 3-Parameter Weibull, $\mathrm{AD}=0.202, p>0.50$ \\
July & 3-Parameter Weibull, $\mathrm{AD}=0.235, p>0.50$ \\
August & Logistic, $\mathrm{AD}=0.301, p>0.25$ \\
September & 3-Parameter Weibull, $\mathrm{AD}=0.333, p>0.50$ \\
October & 3-Parameter Weibull, $\mathrm{AD}=0.249, p>0.50$ \\
November & Largest Extreme Value, $\mathrm{AD}=0.424, p>0.25$ \\
December & Largest Extreme Value, $\mathrm{AD}=0.760, p=0.045$ \\
\hline
\end{tabular}

the time series of process understudy [26]. So, the next section describes change point analysis approach for wind speed data.

\section{Change Point Analysis}

A combination of cumulative sum charts (CUSUM) and change point analysis [27] provides comparative information of different types of time series data. It also provides useful results for climate time series. Here we use this analysis approach for analyzing urban average wind speed data series. There are numerous approaches to perform a change-point analysis. The one used in this paper has been implemented in Taylor (2000) which, is an iterative application of CUSUM and bootstrapping methods to detect changes in time series and their inferences based on the mean-shift model and assuming that residuals are independent and identically distributed with a mean of zero. This software was used to perform the analyses in this paper [28].

Table 5 Showing change point years for each Month wind data series.

Table 5 gives the detail of change point analysis for each month from 1961 to 2010 . It is clear from this table that almost every month shows change in the early 90s near 1992. It is well known that global temperature data also revealed record increase in the global high temperatures during early and mid $90 \mathrm{~s}$. We can say that due to the global climate impact the local coastal wind speed pattern has been changing. The two changes in the pattern 
Table 5. Change point analysis for month wind speed data from 1961 to 2010.

\begin{tabular}{|c|c|c|c|c|c|c|c|c|c|c|c|c|}
\hline \multicolumn{13}{|c|}{ Urban Average Monthly Wind Speed Series (1961-2010) Change Point Analysis Summary } \\
\hline Year & Jan & Feb & Mar & Apr & May & Jun & Jul & Aug & Sep & Oct & Nov & Dec \\
\hline 1972 & & & & $\mathrm{Y}$ & & & & & & & & Y \\
\hline \multicolumn{13}{|l|}{1974} \\
\hline 1977 & Y & & & Y & Y & & & & Y & & Y & \\
\hline \multicolumn{13}{|l|}{1980} \\
\hline 1981 & & & & & & & & Y & & & & \\
\hline \multicolumn{13}{|l|}{1982} \\
\hline \multicolumn{13}{|l|}{1983} \\
\hline \multicolumn{13}{|l|}{1984} \\
\hline 1985 & & & & & & $\mathrm{Y}$ & & & & & & \\
\hline \multicolumn{13}{|l|}{1986} \\
\hline \multicolumn{13}{|l|}{1987} \\
\hline 1992 & $\mathrm{Y}$ & $\mathrm{Y}$ & & Y & & $\mathrm{Y}$ & $\mathrm{Y}$ & $\mathrm{Y}$ & & & $\mathrm{Y}$ & $\mathrm{Y}$ \\
\hline 1995 & & & & & & & $\mathrm{Y}$ & & & $\mathrm{Y}$ & & \\
\hline 1999 & & & $\mathrm{Y}$ & & $\mathrm{Y}$ & & & & & & & \\
\hline \multicolumn{13}{|l|}{2001} \\
\hline \multicolumn{13}{|l|}{2005} \\
\hline \multicolumn{13}{|l|}{2009} \\
\hline Years & 2 & 1 & 1 & 3 & 2 & 2 & 2 & 2 & 1 & 1 & 2 & 2 \\
\hline
\end{tabular}

of wind speed data (1961-2010) in the month of January, as depicted in Figure 1(a), are represented by the shifts in the shaded background. The shaded background represents a region expected to contain all the values based on the current model that two changes occurred. Similar changes can be observed in all figures for the remaining months of the year. Thus, change point analysis reveals that it the most recent 25 years where the wind speed changed its pattern.

Following graphs Figures 1(a)-(l) show graphical presentation of the results of the change-point analysis of the monthly urban wind speed data series.

\section{Results and Discussion}

Three methods were conducted to investigate the impact of global climate change on the fluctuating pattern of average urban wind speed. Trend analysis revealed that for the earlier 25 years (1961-1985) data January, March, May, August, November and December and annual wind speed data have shown the statistically significant negative trends. But, summer season has shown the positive trend for wind speed. Similarly, the most recent 25 years demonstrate no trend for the months from July to Sep- tember the wind speed data due to the monsoon season. In this era, nine months of the year, annual and both winter and summer seasons wind speed data have shown positive trends. Also, the rate of increase of wind speed in the summer season is almost six times higher as compared to the rate of increase of wind speed in the winter season. The trends seem to reveal impact of global climate change on local urban monthly average wind speed observations as there are no high rise buildings near the data collection site. So, the most recent 25 years data revealed the influence of global warming on local coastal wind speed.

Table 3 has demonstrated the trends of average monthly, annual, and seasonal wind speed for the complete data set. It revealed very important results regarding trends. The trends of winter and summer seasons wind speed are positive. Here, the rate of increase of wind speed in the summer season is almost nine times higher as compared to the rate of increase of wind speed in the winter season. But, annual wind speed observations show no trend. Significant positive trends have been observed in March, April and October. In the three data sets, summer season wind speed trend is positive indicating 

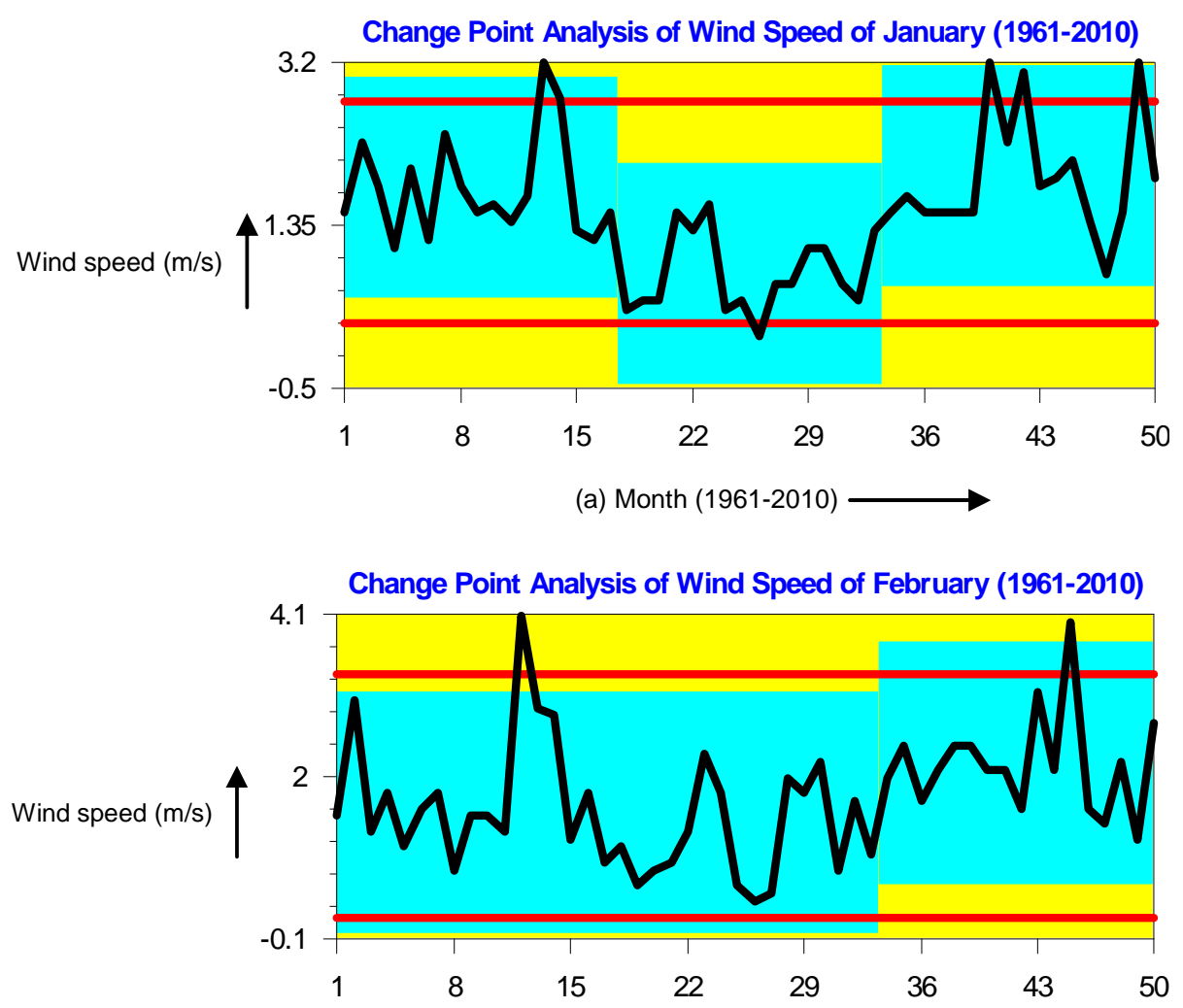

(b) Month (1961-2010)
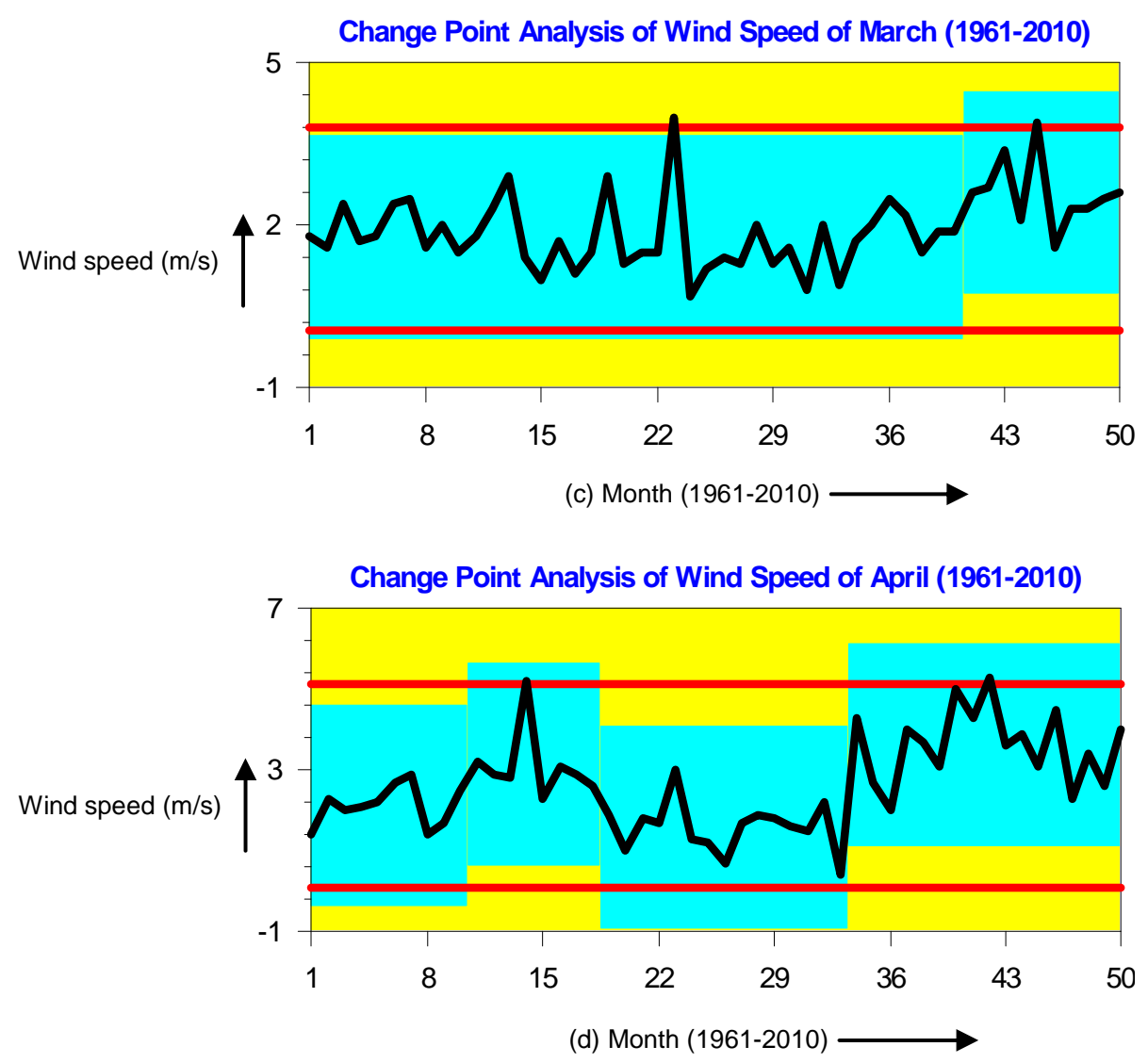


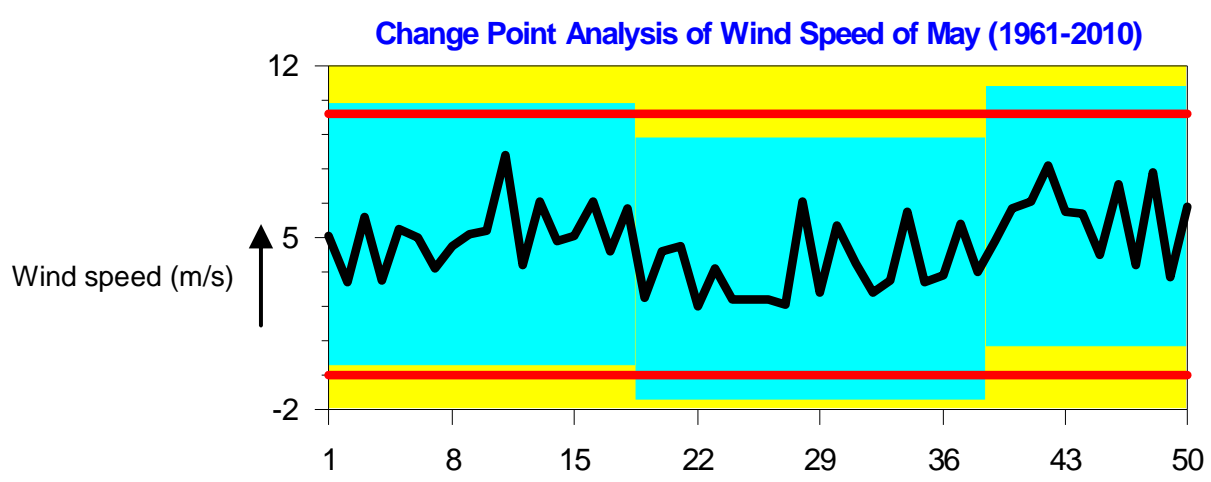

(e) Month (1961-2010)

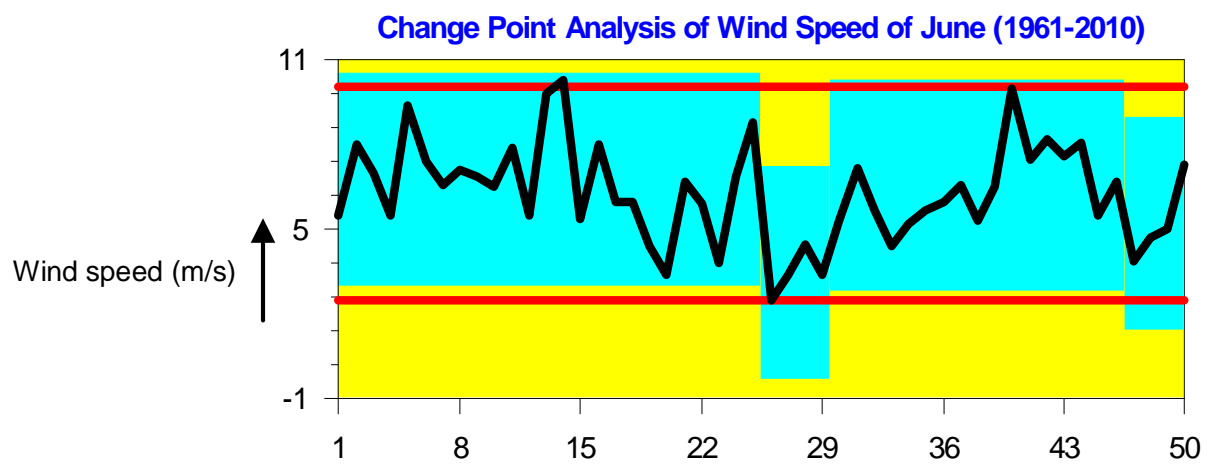

(f) Month (1961-2010)

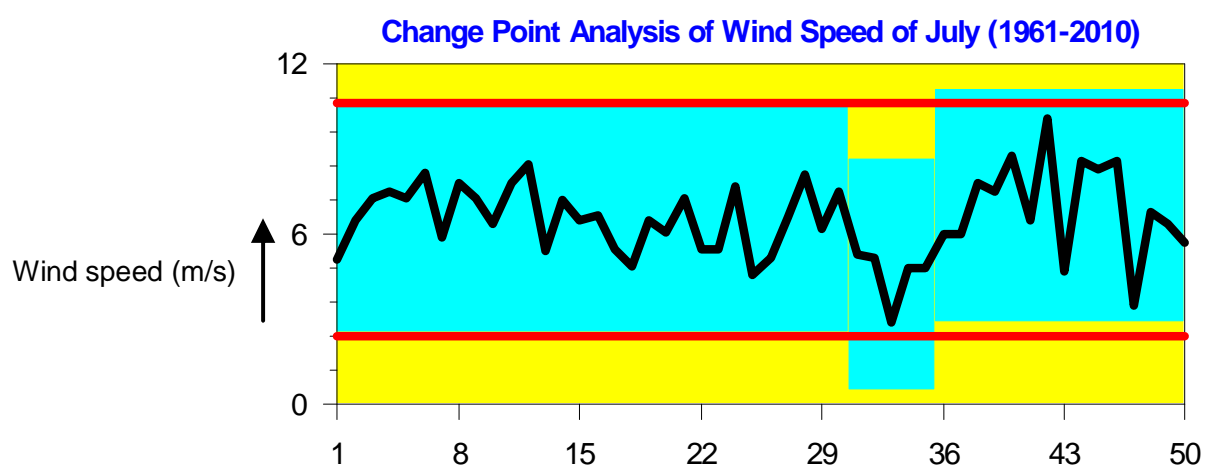

(g) Month (1961-2010)

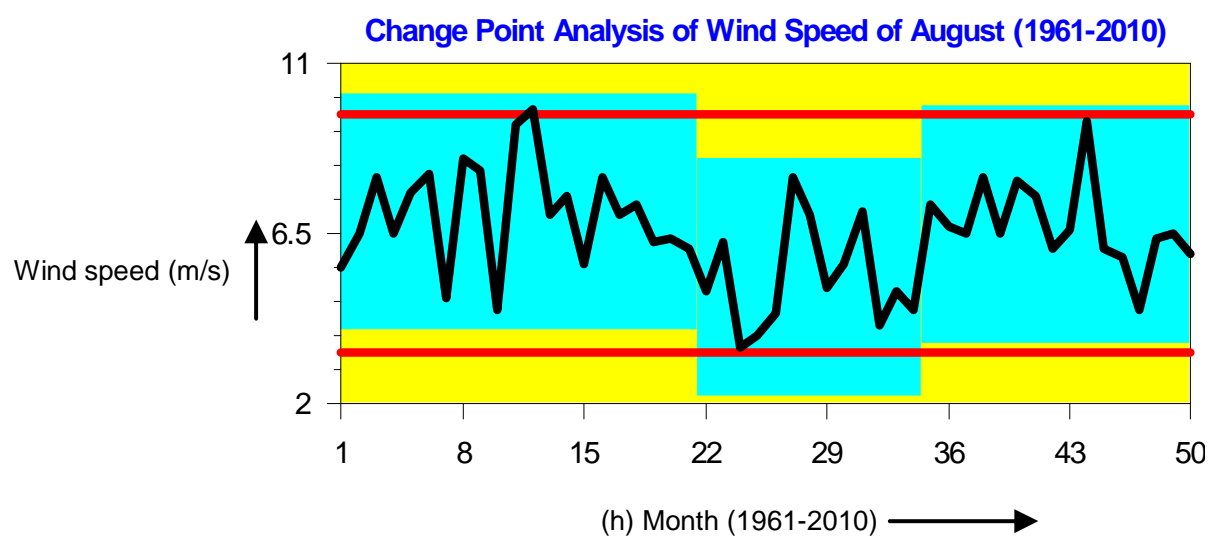



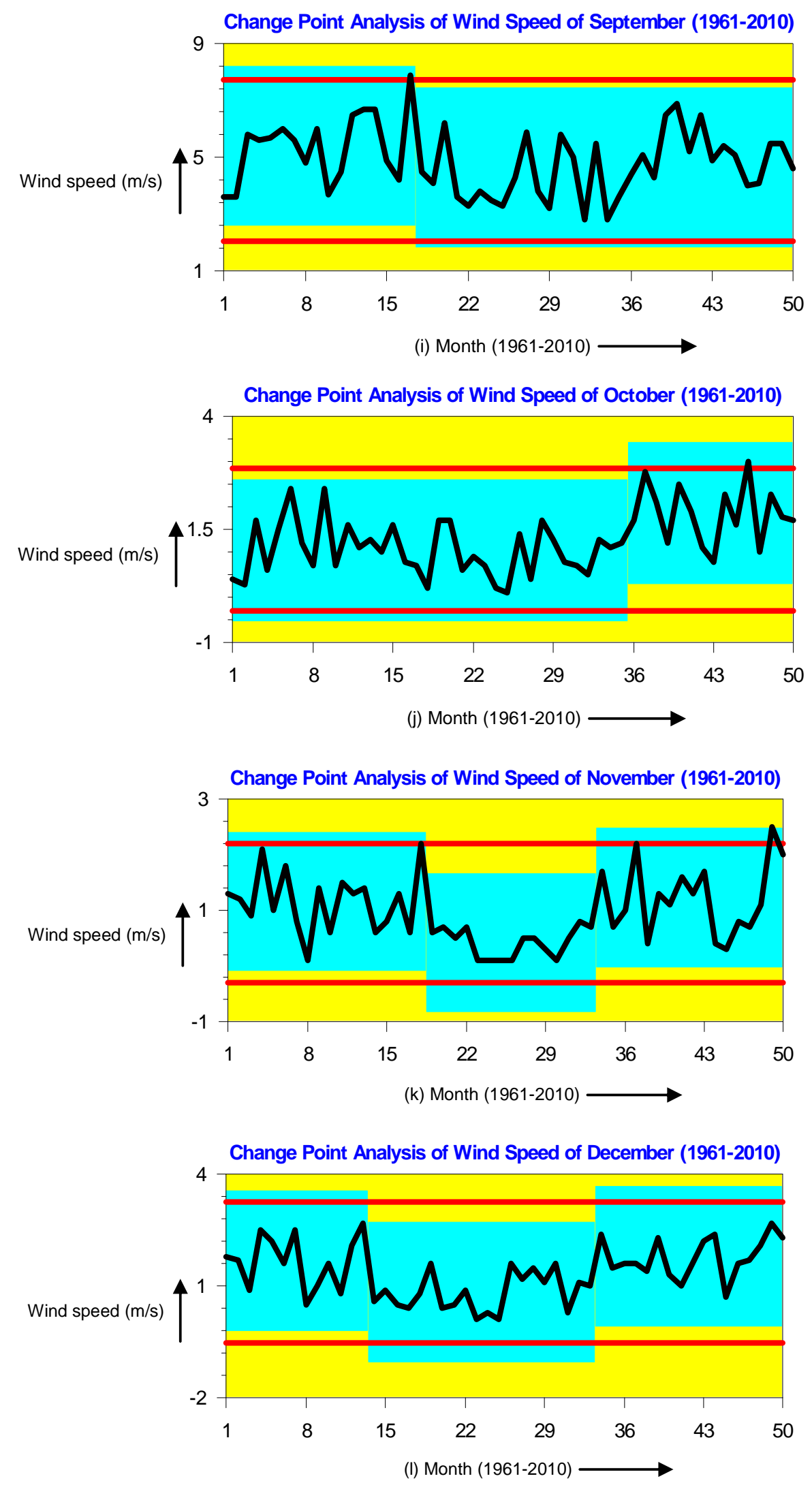

Figure 1. (a) to (l) showing graphical presentation of the results of the change-point analysis of the monthly urban wind speed data series. 
impact of global warming on local climatic parameters during summer.

If different probability distribution functions were fitted to wind speed data, it revealed that in the month of March, the average monthly wind speed data followed Log-normal distribution showing a multiplicative nature of underlying physical process, whereas the wind speed in the months of November and December followed Largest Extreme Value distribution indicating that it would show higher trends.

Results of the change point analysis (see Figures 1(a)(l)) have been summarized in Table 5. It is clear from this table that almost every month shows change in the early 90 s near 1992 . We can say that due to the global climate impact the local coastal wind speed pattern has been changing. The two changes in the pattern of wind speed data (1961-2010) in the month of January, as depicted in Figure 1(a), are represented by the shifts in the shaded background. The analysis performed by change point analysis has also confirmed that wind speed pattern has changed in the most recent 25 years. The trends and underlying probability distribution models of urban wind speed data cannot predict specific events but for some types of extremes they can indicate how the urban wind speed profiles are likely to change in the future.

\section{Conclusions and Future Outlook}

As discussed in Section 1, the effects of global warming and climate change is complex in nature and not completely understood. However, the urban wind data series show different fluctuating pattern in three wind series data. The wind series data during 1986 and 2010, the most recent era, depict significant positive trends probably because of the consequences of global climate change, and is also important in indicating the possible future wind fluctuations in the area under study. Underlying distributions of wind speed also revealed the overall increasing trends both in annual and monthly wind speed fluctuations. Change point analysis of wind data confirmed that some change in fluctuating pattern of physical process has taken place in the most recent era. Analysis performed on urban wind speed pattern showed that somewhere in 1992 the wind speed pattern changed its speed probably due to global climate impact.

Finally, we can say that in the vicinity of Karachi, it appeared to increase the average wind speed pattern due to changes in global climate as the city of Karachi is located at the coast of Arabian Sea. Methods and techniques employed to study local wind speed fluctuations phenomenon has provided an increase in the skills and knowledge necessary to deal with possible future local and global climate change. In the future, knowledge of urban climate change will be of importance for the residents of mega cities. Larger cities will likely emphasize the climatic effects, especially if the urban growth occurs at present pace. The knowledge and understanding about these important climatic factors would help us in forecasting the future direction of wind pattern dynamics, which will help in mitigation of consequences of both local and global climate change in future.

\section{Acknowledgements}

We thank Pakistan Meteorological Department, Karachi, for providing us urban wind speed, and tropical cyclone data.

\section{REFERENCES}

[1] M. A. Hussain, "Mathematical Aspects of The Impact of Urban Greenhouse Gas Emissions on Global Warming," Ph.D. Thesis, Federal Urdu University of Arts, Science and Technology, Karachi, 2006.

[2] M. A. Hussain and M. R. K. Ansari, "Some Insights of Local and Global Temperatures Dynamics," Arabian Journal for Science and Engineering, Vol. 35, No. 1A, 2010, pp. 103-113.

[3] M. A. Hussain and M. R. K. Ansari, "Statistical Aspects of Global Warming Dynamics," Arabian Journal for Science and Engineering, Vol. 32, No. 2A, 2007, pp. 189201.

[4] M. A. K. Yousuf Zai, M. A. K. Ansar, J. Quamar, J. Iqbal and M. A. Hussain, "Predicting the Variations in the Wavelength Structures of the Incoming Radiation Due to Ozone Layer Depletion at Arabian Sea," The Nucleus, Vol. 45, No. 1, 2008, 7 p.

[5] M. A. K. Yousuf Zai, M. A. K. Ansari, J. Quamar, J. Iqbal and M. A. Hussain, "Comparison of AR Strategy with that of Regression Approach for Determining Ozone Layer Depletion as a Physical Process," The Nucleus, Vol. 45, No. 2, 2008, 7 p.

[6] R. Meldensohn, et al., "The Impact of Climate Change on Global Tropical Cyclone Damage," Nature Climate Change, Vol. 2, No. 10, 2012, pp. 205-209. doi:10.1038/nclimate 1357

[7] M. A. Hussain, et al., "Persistency Analysis of Cyclone History in Arabian Sea," The Nucleus, Vol. 48, No. 4, 2011, pp. 273-277.

[8] M. A. Hussain, et al., "Forecast Models for Urban Extreme Temperatures: Karachi Region as a Case Study," The Nucleus, Vol. 47, No. 4, 2010, pp. 301-311.

[9] M. A. Hussain, et al., "Arabian Seawater Temperature Fluctuations in the Twentieth Century," Journal of Basic and Appliewd Sciences, Vol. 8, No. 1, 2012, pp. 105-109. doi:10.6000/1927-5129.2012.08.01.24

[10] S. H. L. Yim, J. C. H. Fung, and A. K. H. Lau, "Mesoscale Simulation of Year-to-Year Variation of Wind Power Potential over Southern China," Energies, Vol. 2, 2009, pp. 340-361. doi:10.3390/en20200340

[11] J. M. Dryden, "Potential Climate Change Impacts on Wind Resources in Oklahoma: A Focus on Future Energy 
Output," Masters Thesis, The University of Oklahoma, Norman, 2008.

[12] Ministry of Petroleum \& Natural Resources, Hydrocarbon Development Institute of Pakistan, "Pakistan Energy Year Book," 2004.

[13] www.urckarachi.org/IEE_Study_of_DHA-WFD_Project (ii).pdf

[14] S.-H. Lee and H.-D. Kim, "Effects of Regional Warming Due to Urbanization on Daytime Local Circulations in a Complex Basin of the Daegu Metropolitan Area, Korea," Journal of Applied Meteorology and Climatology, Vol. 47, No. 5, 2008, pp. 1427-1441. doi:10.1175/JAMC1504.1

[15] ftp://ftp1.esrl.noaa.gov/users/.../Liu\&Curry_manu_r1\%20 1.doc

[16] http://www.globalchange.gov/images/cir/pdf/National.pdf

[17] S. Qureshi, "The Fast Growing Megacity Karachi as a Frontier of Environmental Challenges: Urbanization and Contemporary Urbanism Issues," Journal of Geography and Regional Planning, Vol. 3, No. 11, 2010, pp. 306321.

[18] M. A. Hussain, et al., "Arabian Seawater Temperature Fluctuations in the Twentieth Century," Journal of Basic and Applied Sciences, Vol. 8, No. 1, 2012, pp. 105-109. doi:10.6000/1927-5129.2012.08.01.24

[19] S. D. Río, A. Cano-Ortiz, L. Herrero and A. Penas, "Recent Trends in Mean Maximum and Minimum Air Temperatures over Spain (1961-2006)," Theoretical and Applied Climatology, Vol. 109, No. 3-4, 2012, pp. 605-626. doi:10.1007/s00704-012-0593-2

[20] M. A. Hussain, S. Abbas and M. R. K. Ansari, "Wind Speed Analysis of Some Coastal Areas near Karachi," Pakistan Academy of Sciences, 2012.

[21] F. A. L. Jowder, "Weibull and Rayleigh Distribution Functions of Wind Speeds in Kingdom of Bahrain," Wind Engineering, Vol. 30, No. 5, 2006, pp. 439-445. doi:10.1260/030952406779502650

[22] H. Basumatary, et al., "Weibull Parameter Estimation: A Comparison of Different Methods," Wind Engineering, Vol. 29, No. 3, 2005, pp. 309-316. doi:10.1260/030952405774354895

[23] http://en.wikipedia.org/wiki/Logistic_distribution

[24] J. V. Seguro and T. W. Lambert, "Modern Estimation of the Parameters of the Weibull Wind Speed Distribution for Wind Energy Analysis," Journal of Wind Engineering and Industrial Aerodynamics, Vol. 85, No. 1, 2000, pp. 75-84. doi:10.1016/S0167-6105(99)00122-1

[25] N. L. Johnson, S. Kotz and N. Balakrishnan, "Continuous Univariate Distributions,” John Wiley, New York, 2004.

[26] Reeves, Jaxk, J. Chen, X. L. Wang, R. Lund and Q. Q. Lu, "A Review and Comparison of Changepoint Detection Techniques for Climate Data," Journal of Applied Meteorology and Climatology, Vol. 46, No. 6, 2007, pp. 900915. doi:10.1175/JAM2493.1

[27] W. A. Taylor, "Change-Point Analyzer 2.0 Shareware program," Taylor Enterprises, Libertyville, 2000. http://www.variation.com/cpa/tech/changepoint.html 